\title{
PHYLOGENY AND RATES OF MOLECULAR EVOLUTION IN THE APHELOCOMA JAYS (CORVIDAE)
}

\author{
A. TOWNSEND PETERSON ${ }^{1}$ \\ Committee on Evolutionary Biology, University of Chicago, Chicago, Illinois 60637, USA
}

\begin{abstract}
I examined hypotheses of Aphelocoma jay phylogeny derived from allozyme data. Results from various algorithms differ in details, but the overall patterns are consistent: Scrub Jays (A. coerulescens) and Unicolored Jays ( $A$. unicolor) were derived independently from different populations of Gray-breasted Jays (A. ultramarina). Within Scrub Jays, the californica subspecies group was derived from the populations of interior North America (woodhouseii group). One Unicolored Jay population and two Scrub Jay populations, all strongly differentiated, are placed consistently at the base of the phylogeny, but phenotypic, biogeographic, and theoretical evidence suggests that these populations represent rapidly evolving populations derived from within populations of their respective species. Because analyses of rates of molecular evolution demonstrate significant rate heterogeneity, I suggest that the application of a molecular clock to date-splitting events in the Aphelocoma jays is not a valid approach. Received 18 February 1991, accepted 3 July 1991.
\end{abstract}

THE THREE species of Aphelocoma jays range throughout western and southern North America and northern Central America (Fig. 1; Pitelka 1951). Scrub Jays (A. coerulescens) range from Oregon and Wyoming south to the Isthmus of Tehuantepec, with disjunct populations on Santa Cruz Island off the coast of southern California and in peninsular Florida. The 15 subspecies form five groups, each characterized by unique combinations of plumage, morphological, and behavioral characters (Fig. 1; Pitelka 1951, Peterson 1991a): (1) woodhouseii group (Wyoming and southeastern Oregon south through Great Basin and along both sides of Rocky Mountains, and then along interior slopes of Sierra Madre Oriental and Sierra Madre Occidental of northern Mexico to southern Chihuahuan Desert and vicinity of Mexico City); (2) californica group (western Oregon, California, and Baja California); (3) sumichrasti group (southern Mexico); (4) coerulescens group (peninsular Florida); and (5) insularis group (Santa Cruz Island). The Gray-breasted Jay (A. ultramarina) ranges throughout the mountains of northern and central Mexico and the southwestern United States. The seven subspecies fall into three groups characterized by unique combinations of morphological and behavioral characters (Fig. 1; Pitelka 1951): (1) potosina group (Sierra Madre Oriental); (2) wollweberi group (Si-

\footnotetext{
${ }^{1}$ Present address: Department of Zoology, Field Museum of Natural History, Roosevelt Road at Lake Shore Drive, Chicago, Illinois 60605, USA.
}

erra Madre Occidental); and (3) ultramarina group (Transvolcanic Belt). Finally, the Unicolored Jay (A. unicolor) consists of five allopatric populations, each a separate subspecies, in southern Mexico and northern Central America (Pitelka 1951).

The Aphelocoma jays have been the subject of numerous comparative studies. Evaluations of social systems in the genus have led to advances in understanding ecological factors important in the evolution of sociality (Woolfenden and Fitzpatrick 1984, Fitzpatrick and Woolfenden 1986, Brown 1987, Peterson and Burt, in press). Differential habitat use in Scrub Jays (Peterson and Vargas 1992) is correlated with geographic variation in beak shape, suggesting that beak shapes have responded to natural selection (Peterson, in prep.). Integration of phylogenetic information into such investigations will allow an important new dimension of understanding (Brooks and McLennan 1990). Hence, I have attempted to estimate the phylogeny of the differentiated forms in the genus.

Rates of molecular evolution.-Since the publication of the influential paper of Zuckerkandl and Pauling (1962), the idea of a "molecular clock" has been controversial in molecular biology and systematics. The clock concept is based on the assumption of a uniform rate of molecular evolution in a group. If the uniform rate assumption were correct, the accumulation of genetic differentiation between sister taxa would be time-invariant, and divergence times could be estimated from genetic distances.

The clock concept is an important feature of 
many sectors of molecular systematics. Attempts have been made to calibrate clocks for a variety of taxa and biochemical data sets (e.g. Sarich 1977, Wilson et al. 1977, Sibley and Ahlquist 1981). Several commonly used treebuilding algorithms depend on the assumption of a clock (Felsenstein 1982, 1989). The molecular clock is now a common method of dating divergence times between taxa (e.g. Zink 1982, Nevo et al. 1987, Johnson and Marten 1988). Hence, a uniform rate of molecular evolution and the consequent existence of a clock can be important assumptions in molecular systematics.

However, the assumption that evolutionary rates are homogeneous often goes untested. If molecular evolutionary rates differ among lineages, the clock becomes unreliable. Equality of rates in sister lineages can be tested with the relative-rate test: in the three-taxon statement ((A, B), C), A and B should show similar degrees of differentiation from C (Wilson et al. 1977). Significant departure from equality indicates that $\mathrm{A}$ and $\mathrm{B}$ have evolved at different rates. Rate uniformity has been tested in a number of taxa, with some studies documenting homogeneity (e.g. Sibley and Ahlquist 1983, Bledsoe 1987), and others finding heterogeneity (e.g. Britten 1986, Sibley et al. 1987, Sheldon 1987, Springer and Kirsch 1989). A uniform rate and molecular clock are commonly and uncritically assumed in systematic studies, so a test of the assumption of rate uniformity was desirable in my study.

\section{METHODS}

Sampling design.-During 1986-1989, I studied and collected Aphelocoma jays at 35 sites in the United States and Mexico. Tissue from the endangered Florida population of Scrub Jays was salvaged from recently dead individuals at nests and roadsides. Samples of heart, liver, and pectoral muscle from each individual were stored in cryotubes in liquid nitrogen. All tissue was deposited in the Frozen Tissue Collection of the Field Museum of Natural History.

In total, I analyzed 615 Aphelocoma jays (458 Scrub Jays, 138 Gray-breasted Jays, and 19 Unicolored Jays). Specimens of Scrub, Gray-breasted, and Unicolored jays were collected at 24, 8 , and 3 sites, respectively, in the United States and Mexico (Table 1, Fig. 1). I attempted to obtain samples of 20 individuals at each site to maximize tree stability (Archie et al. 1989): Scrub Jay samples averaged 19.2 (range 13-27) individuals; Gray-breasted Jay samples averaged 17.3 (range 7-22) individuals; and Unicolored Jay samples

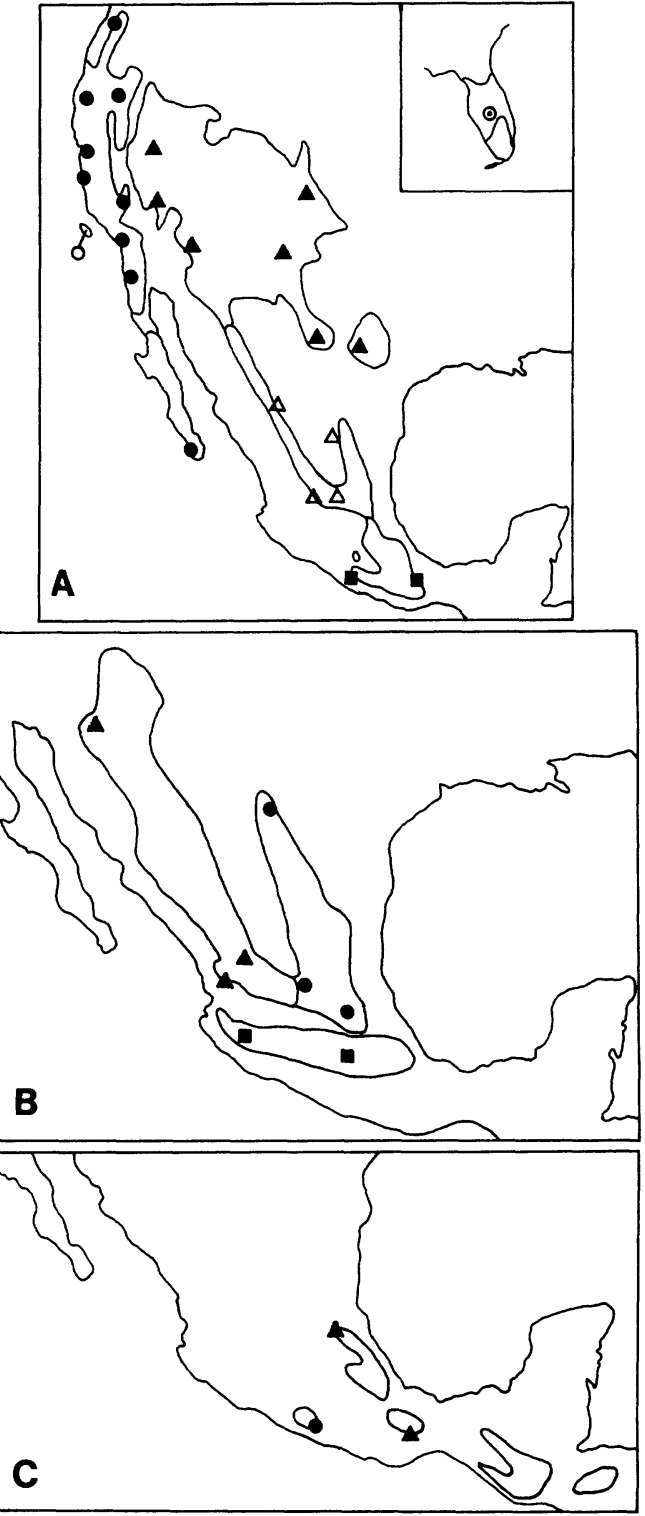

Fig. 1. Summary of collecting localities and subspecies groups of three species of Aphelocoma jays; Florida range indicated in upper right-hand corner. (A) Scrub Jays: open circle, Santa Cruz Island (ACINS); closed circles; californica group (CO CAL); closed triangles, northern woodhouseii group (CO WOO); open triangles, southern woodhouseii group (CO MEX); squares, sumichrasti group; dotted circle, Florida (ACCO2). (B) Gray-breasted Jays: triangles, wollweberi group (UL WOL); circles, potosina group (UL POT); squares, ultramarina group (UL ULT). (C) Unicolored Jays: triangles, east slope populations (UN E); circle, west slope population (ANGUE). 
TABLE 1. Sample localities and sample sizes (complete locality data in Peterson 1990).

\begin{tabular}{|c|c|c|c|}
\hline Group & Sample & Locality & $\begin{array}{l}\text { Sample } \\
\text { size }\end{array}$ \\
\hline \multicolumn{4}{|l|}{ Scrub Jays } \\
\hline CO CAL & $\begin{array}{l}\text { ACCAL } \\
\text { ACCAU } \\
\text { ACHY3 } \\
\text { ACIMM } \\
\text { ACOBC } \\
\text { ACOBk } \\
\text { ACOOC } \\
\text { ACSP1 } \\
\text { ACSP3 }\end{array}$ & $\begin{array}{l}\text { CA, Monterey Co., Bradley } \\
\text { CA, Trinity Co., Hyampom } \\
\text { BCS, Sierra de la Laguna } \\
\text { OR, Adair Village } \\
\text { CA, Orange Co., Silverado Canyon } \\
\text { BCN, Rosa de Castilla (Ojos Negros) } \\
\text { CA, San Ramon } \\
\text { CA, Alturas } \\
\text { CA, Bodfish }\end{array}$ & $\begin{array}{l}24 \\
16 \\
16 \\
15 \\
16 \\
20 \\
16 \\
22 \\
19\end{array}$ \\
\hline CO MEX & $\begin{array}{l}\text { ACCY1 } \\
\text { ACCY2 } \\
\text { ACGR1 } \\
\text { ACGR3 }\end{array}$ & $\begin{array}{l}\text { COA, El Diamante Pass } \\
\text { SLP, Sierra de Bledos } \\
\text { DUR, Villa Ocampo } \\
\text { JAL, Lagos de Moreno }\end{array}$ & $\begin{array}{l}21 \\
21 \\
21 \\
20\end{array}$ \\
\hline CO WOO & $\begin{array}{l}\text { ACNE1 } \\
\text { ACNE4 } \\
\text { ACNE6 } \\
\text { ACTEX } \\
\text { ACWO1 } \\
\text { ACWO3 } \\
\text { ACWO4 }\end{array}$ & $\begin{array}{l}\text { NV, Toiyabe Mountains } \\
\text { NV, Mt. Charleston } \\
\text { AZ, Drake } \\
\text { TX, Edwards Plateau, Carta Valley } \\
\text { CO, Front Range, Gardner } \\
\text { NM, Manzano Mountains } \\
\text { TX, Davis Mountains }\end{array}$ & $\begin{array}{l}14 \\
27 \\
25 \\
22 \\
11 \\
26 \\
21\end{array}$ \\
\hline CO SUM & $\begin{array}{l}\text { ACREM } \\
\text { ACSM2 }\end{array}$ & $\begin{array}{l}\text { GRO, Xocomanatlán } \\
\text { OAX, Sierra de los Mijes, Zempoaltépetl }\end{array}$ & $\begin{array}{l}13 \\
20\end{array}$ \\
\hline- & ACINS & CA, Santa Cruz Island & 14 \\
\hline- & $\mathrm{ACCO} 2$ & FL, Archbold Biol. Station & 18 \\
\hline \multicolumn{4}{|c|}{ Gray-breasted Jays } \\
\hline UL WOL & $\begin{array}{l}\text { AUAZ1 } \\
\text { AUGRA } \\
\text { AUWO1 }\end{array}$ & $\begin{array}{l}\text { AZ, Peña Blanca Lake } \\
\text { JAL, Sierra de Bolaños } \\
\text { ZAC, Valparaiso }\end{array}$ & $\begin{array}{r}16 \\
7 \\
20\end{array}$ \\
\hline UL POT & $\begin{array}{l}\text { AUCO2 } \\
\text { AUPO2 } \\
\text { AUPO3 }\end{array}$ & $\begin{array}{l}\text { COA, Sierra El Carmen } \\
\text { SLP, Sierra de Bledos } \\
\text { HID, Jacala }\end{array}$ & $\begin{array}{l}22 \\
22 \\
20\end{array}$ \\
\hline UL ULT & $\begin{array}{l}\text { AUULT } \\
\text { AUCOL }\end{array}$ & $\begin{array}{l}\text { MOR, Huitzilac } \\
\text { JAL, Sayula }\end{array}$ & $\begin{array}{l}14 \\
17\end{array}$ \\
\hline \multicolumn{4}{|c|}{ Unicolored Jays } \\
\hline 一 & ANGUE & GRO, Sierra de Atoyac & 7 \\
\hline UN E & $\begin{array}{l}\text { ANOAX } \\
\text { ANCON }\end{array}$ & $\begin{array}{l}\text { OAX, Sierra de los Mijes, Zempoaltépetl } \\
\text { HID, Sierra de la Huasteca, Tlanchinol }\end{array}$ & $\begin{array}{r}10 \\
2\end{array}$ \\
\hline
\end{tabular}

averaged 6.3 (range $2-10$ ) individuals. To avoid problems with nonindependence of individual genotypes when related individuals (e.g. parents and offspring, multiple siblings) were collected, I included only one member of each potentially related pair of individuals.

For convenience in referring to population samples, I assigned each a five-letter code, in which the first letter indicates the genus, the second indicates the species, and the remaining three indicate subspecies and (if necessary) the sample from that subspecies (e.g. ACNE2 is the second sample of Aphelocoma coerulescens nevadae; Table 1). For reference to larger infraspecific divisions, I divided the species in a manner equivalent to the subspecies groups of $\mathrm{Pi}-$ telka (1951), except that the woodhouseii group was divided into northern (United States populations) and southern (Mexican populations) parts (Fig. 1, Table 1).

To provide outgroups for phylogenetic analyses, I included 70 individuals of 17 other corvid species. To maximize detection of plesiomorphic alleles for potentially closely related genera (Hardy 1969, Hope 1989), I included all material available (up to 20 individuals) of each of the following species: Cyanocitta cristata, C. stelleri, Cyanolyca mirabilis, C. cucullata, C. 
viridicyana, and Gymnorhinus cyanocephalus. For less closely related corvid genera, I included one or two individuals of each species available: Calocitta formosa, C. colliei, Cyanocorax violaceus, C. cyanomelas, C. yncas, Corvus brachyrhynchos, C. cryptoleucus, Pica pica, P. nuttallii, Nucifraga columbiana, and Perisoreus canadensis.

Electrophoresis.-I homogenized approximately $0.4 \mathrm{~g}$ each of heart, muscle, and liver from each sample in a $1 \mathrm{mM}$ disodium EDTA/100 $\mathrm{mM}$ Trizma base/0.2 mM NAD, NADP, and ATP buffer. Homogenates were centrifuged at $12,000 \mathrm{rpm}$ for $30-45 \mathrm{~min}$. Supernatants were drawn into capillary tubes, and stored at $-76^{\circ} \mathrm{C}$ for later use. Gels for electrophoresis were made of 10-12\% starch in the appropriate buffer. After electrophoresis, gels were sliced, and stained differentially following Shaw and Prasad (1970) and Harris and Hopkinson (1978). Loci studied included ACON (enzyme number 4.2.1.3; Harris and Hopkinson 1978), ACP (3.1.3.2), ADA (3.5.4.4), ADH (1.1.1.1), AK (2 loci, 2.7.4.3), CK (2 loci, 2.7.3.2), ES (2 loci, 3.1.1.1), FUM (2 loci, 4.2.1.2), GDA (3.5.4.3), GOT (2.6.1.1), GPD (1.1.1.8), GPI (5.3.1.9), IDH (1.1.1.42), LDH (2 loci, 1.1.1.27), MDH (2 loci, 1.1.1.37), MPI (5.3.1.8), PEP (leucyl-alanine, 2 loci; leucyl-aminopeptide, 1 locus; 3.4.11), PGD (1.1.1.44), PGM (2.7.5.1), SOD (1.15.1.1), and SORDH (1.1.1.14). Details of electrophoretic conditions are given in Peterson (1990). Loci showing difficult-to-interpret patterns of variation were excluded. Stained gels were digitized with an optical imaging system, and visual images were stored in computer files; gels were later discarded.

To assure correct assignment of homologies, I included reference individuals on each gel. Alleles from different populations were not considered equivalent until found indistinguishable in side-by-side comparisons on the same gel. I rechecked homology assignments for each locus under different buffer conditions and/or at maximum migration distances (an average of two recheck runs per variable locus; $\mathrm{Pe}$ terson 1990).

Tree-building analyses. - I employed a variety of methods to estimate phylogenetic relationships of the Aphelocoma jays. I began with simple methods with restrictive assumptions; then, with successively more complex approaches, I attempted to relax these assumptions. I initially analyzed relationships of all 35 population samples, but later combined individual samples and investigated relationships of the groups of samples described above.

Although an explicit test of the monophyly of the Aphelocoma jays has yet to be conducted, several lines of evidence indicate that the group is monophyletic. Several characters of plumage, vocalizations, and morphology are characteristic of Aphelocoma jays ( $\mathrm{Pi}$ telka 1951). Hope (1989) found that Aphelocoma, Cyanocitta, and Gymnorhinus form a well-supported group based on phylogenetic analysis of qualitative and mensural osteological characters. Aphelocoma and $\mathrm{Cy}$ anocitta share a synapomorphy (a new bony element in the sclerotic ring; Curtis and Miller 1938) not present in Gymnorhinus (Peterson, unpubl. data). While Cyanocitta has a number of unique features, Aphelocoma is not so well defined. Because it seems unlikely that Cyanocitta was derived from within Aphelocoma, I assume for the purposes of this paper that Aphelocoma is monophyletic.

I performed phenetic analyses on matrices of modified Rogers' genetic distances (as modified by Wright 1978), which were calculated using programs developed by Scott M. Lanyon. Allele-frequency data and genetic-distance matrices are available in Peterson (1990) or on request from the author. Exploratory analyses based on other genetic distance measures either produced similar results (e.g. Cavalli-Sforza chord distance) or were difficult to interpret (e.g. Nei's genetic distance), so I report only results from Rogers' distances. Two different clustering methods, the unweighted pair-group method (UPGMA) and singlelinkage cluster analysis, were applied to the genetic distance matrix using NTSYS-pc (version 1.40; Rohlf 1988).

One potential problem with strictly phenetic methods is the assumption of equal evolutionary rates in each lineage (Felsenstein 1982). A first step in relaxing this assumption is the Fitch-Margoliash algorithm, which allows for some variation in evolutionary rates (Fitch and Margoliash 1967, Felsenstein 1989). I used Steller's Jays (Cyanocitta stelleri, CYSTE) as the outgroup, because it is sufficiently close phylogenetically to be informative, and the sample size (20) was sufficiently large to permit accurate estimation of gene frequencies. Because of limited computer memory, the entire data set could not be analyzed at one time, so I analyzed subsets of the data in two ways. I either assumed species to be monophyletic and analyzed each separately, or I used representative populations from each of the subspecies groups. All trees were checked for stability using a jackknife manipulation (Lanyon 1985), in which the data were reanalyzed sequentially omitting each ingroup taxon and the resulting trees combined by strict consensus using programs developed by Scott M. Lanyon to complement those of PHYLIP (Felsenstein 1989).

Cladistic analysis of electrophoretic data is difficult both logically and methodologically, chiefly because of problems with the treatment of polymorphic characters (Buth 1984, Swofford and Berlocher 1987, Swofford and Olsen 1990). Computer packages such as PAUP deal with the problem by selecting the mostparsimonious character state from among the possibilities and ignoring potentially conflicting information in other alleles present in the population (D. Swofford, pers. comm.). Because loci in my study were highly polymorphic (Peterson 1990), coding loci as characters would not be very informative; instead, I chose to code alleles as characters.

Using the heuristics/subtree-pruning and regrafting branch-swapping option of PAUP (version 3.0; 
TABLE 2. Matrix of character states representing presence and absence of 38 phylogenetically informative alleles at 29 loci in 35 Aphelocoma jay populations and a composite outgroup.

\begin{tabular}{|c|c|c|c|c|}
\hline Sample & 1 & 11 & 21 & 31 \\
\hline OUTGR & ?110010110 & 0100011000 & 0000001000 & 00100000 \\
\hline ACCAL & 0000010000 & 0001110000 & 0100111000 & 00000110 \\
\hline ACCAU & 0000000000 & 1000110100 & 0000010000 & 00000100 \\
\hline $\mathrm{ACCO} 2$ & 0100000000 & 0000010000 & 0010000000 & 01000000 \\
\hline ACCY1 & 0100000000 & 0000010001 & 0000011001 & 00011111 \\
\hline ACCY2 & 0100000000 & 0010010001 & 0100011000 & 10000100 \\
\hline ACGR1 & 0000110100 & 1010010001 & 0100011000 & 10000110 \\
\hline ACGR3 & 0000000000 & 0000010000 & 0101011000 & 10000110 \\
\hline $\mathrm{ACHY} 3$ & 0000010000 & 0000110000 & 0110011000 & 00110010 \\
\hline ACIMM & 0000000000 & 0000110000 & 0000011000 & 00000010 \\
\hline ACINS & 0000000000 & 0000010000 & 0000000000 & 00000000 \\
\hline ACNE1 & 1000010110 & 0000010000 & 0010011110 & 00000110 \\
\hline ACNE4 & 0000010100 & 0000010101 & 0110011111 & 00000110 \\
\hline ACNE6 & 0000000010 & 0000010000 & 0010011000 & 00000110 \\
\hline $\mathrm{ACOBC}$ & 1000000001 & 0000110000 & 1010011000 & 00000111 \\
\hline $\mathrm{ACOBk}$ & 0010000000 & 0000110000 & 0000010000 & 00001010 \\
\hline ACOOC & 0000100000 & 1000010001 & 0000111000 & 00000110 \\
\hline ACREM & 0000000010 & 0000010000 & 0000011000 & 01000000 \\
\hline ACSM2 & 0000100010 & 0000010010 & 0000011000 & 01101000 \\
\hline ACSP1 & 1000000000 & 1000110100 & 0000011010 & 00000111 \\
\hline ACSP3 & 0000000000 & 0000110000 & 0000011000 & 00001110 \\
\hline ACTEX & 0000000000 & 0000010000 & 0000011000 & 00000010 \\
\hline ACWO1 & 1000000000 & 0000010001 & 0001001010 & 00000110 \\
\hline $\mathrm{ACWO} 3$ & 0000000001 & 0010010001 & 0010011010 & 10000110 \\
\hline ACWO4 & 1000000000 & 0010010101 & 0000001110 & 00000110 \\
\hline AUPO3 & 0000001000 & 0000010010 & 0000011100 & 00000000 \\
\hline AUGRA & 0000001000 & 0000011000 & 0000001000 & 00000000 \\
\hline AUCOL & 0000000000 & 0100001000 & 0000001000 & 00000000 \\
\hline AUULT & 0000000000 & 0000001000 & 0000011000 & 00100000 \\
\hline AUPO2 & 0011000000 & 0000010010 & 1000011100 & 00000000 \\
\hline AUWO1 & 0000001000 & 0000011010 & 0000001000 & 00000000 \\
\hline AUAZ1 & 0000000000 & 0000001000 & 0000000000 & 00000000 \\
\hline AUCO2 & 1001000000 & 0000011010 & 0000011100 & 00000000 \\
\hline ANCON & 0000000000 & 0001001000 & 0000000000 & 00000000 \\
\hline ANOAX & 0000000000 & 0100001000 & 0000011000 & 00000000 \\
\hline ANGUE & 0000000000 & 0000001000 & 0000000000 & 00000000 \\
\hline
\end{tabular}

Swofford 1989), I analyzed a binary coding of 102 alleles from 29 loci (Table 2). Of these alleles, 38 were potentially informative about relationships among ingroup taxa. This approach can have the undesirable consequence of hypothetical ancestors lacking alleles at particular loci (Buth 1984, Swofford and Berlocher 1987). However, this problem can be ignored if population samples are large enough that the presence or absence of one allele in the sample can be assumed to be independent of the presence of other alleles. In other words, the alleles under study were indeed lacking in those problematic hypothetical ancestors, and some other allele is assumed to have been present at that particular locus.

If the assumption of independence of alleles at a locus were unreasonable, weighting alleles so that each locus contributes equally to the analysis would be desirable. In this particular data set, however, preliminary runs indicated that weighting serves only to overemphasize loci with few alleles and deem- phasize apparently informative alleles at loci with more alleles. Hence, succeeding analyses were based on unweighted presence-and-absence data for alleles. I used a composite outgroup representing allele presences and absences in all outgroup taxa to root resulting trees. All data sets were tested for significant phylogenetic information with the randomization tests of Archie (1989). To assess the stability of nodes on the resulting trees, a jackknife manipulation (Lanyon 1985) was conducted, in which the analyses were repeated sequentially omitting each of the ingroup taxa. In each repetition, the heuristic search was allowed to run to completion, with up to 2,500 trees stored for branch-swapping, and the resulting 35 sets of 13 to 2,500 equally-parsimonious trees were combined using a majority-rule consensus.

One problem plaguing cladistic analyses of electrophoretic data is failure to detect alleles actually present in populations because of inadequate sampling (Swofford and Berlocher 1987). This nondetec- 
TABLE 3. Matrix of character states representing presence and absence of 33 phylogenetically informative alleles at 29 loci in eight subspecies groups of Aphelocoma jays and a composite outgroup.

\begin{tabular}{|c|c|c|c|c|}
\hline Sample & 1 & 11 & 21 & 31 \\
\hline OUTGR & $? 110010110$ & 1001100000 & 0000000100 & 000 \\
\hline $\mathrm{CO} \mathrm{CAL}$ & 1011100011 & 0011010111 & 1010100111 & 111 \\
\hline CO WOO & 1000101110 & 0101010101 & 1111111000 & 110 \\
\hline CO MEX & 0101101001 & 0101000101 & 0110011011 & 111 \\
\hline CO SUM & 0001000100 & 0001001000 & 0010000101 & 000 \\
\hline UL POT & 1010010000 & 0001101010 & 0011000000 & 000 \\
\hline UL WOL & 0000010000 & 0001101000 & 0000000000 & 000 \\
\hline UL ULT & 0000000000 & 1000100000 & 0010000100 & 000 \\
\hline UNICE & 0000000000 & 1010100000 & 0010000000 & 000 \\
\hline
\end{tabular}

tion causes extra homoplasy in the resulting trees in the form of "reversals," which are actually undetected synapomorphic alleles. In my study, several population samples were available from most of the subspecies groups, which reduced considerably the probability of nondetection of alleles. I conducted a cladistic analysis of relationships among regions within the three species (i.e. subspecies groups; Fig. 1, Table 1) by combining all alleles found in populations of each region into a subspecies group (Table 3 ). I found 33 alleles to be phylogenetically informative about relationships of ingroup taxa (Table 3). Results based on other phylogeny-estimation algorithms, such as the polymorphism parsimony of Felsenstein (1979), yielded similar results, and are not presented below.

Rate tests. - I tested for evolutionary rate uniformity by focusing on three populations previously identified as distinctive in studies of genetic differentiation (Peterson 1990): Scrub Jays from Florida; Scrub Jays from Santa Cruz Island; and Unicolored Jays from Guerrero. The hypothesis tested was that historical independence of lineages could account for zones of extreme genetic differentiation among populations of Aphelocoma jays. Using three-taxon statements from the phylogenetic results, I conducted relative-rate tests that compared genetic distances in all representatives of the two taxa connected by the interior node of these trees to all representatives of the third taxon. Because at least two of the groups are represented by numerous population samples, replicate comparisons were possible.

To visualize patterns of nonuniformity of rates, I also estimated branch lengths and their variability for two subspecies-group phylogenies with a resampling technique. The resampling manipulation was an attempt to estimate how robust branch-length estimates are to choice of populations for sampling. I used the user-tree option of the FITCH program in PHYLIP to estimate branch lengths in 30 replicate analyses. Each replicate included ACINS, ANGUE, ACCO2, and randomly selected population samples representing each of the remaining eight subspecies groups (Table 1). The wollweberi group of Gray-breasted Jays was excluded from some analyses because it is part of an unresolved trichotomy in some trees, and the user-tree option of PHYLIP requires dichotomous branching at internal nodes. Branch lengths from the replicate analyses were compared using Mann-Whitney $U$-tests.

\section{RESULTS}

Phenetic methods. - The two phenetic analyses differed in the placement of a few groups and in the degree of resolution (Fig. 2). However, both established one cluster that consisted of populations of the californica group of Scrub Jays, and another of populations of the woodhouseii and sumichrasti groups of Scrub Jays (Pitelka 1951). The only exceptions are the inclusion of the populations of the southern tip of Baja California and northwestern California ( $\mathrm{ACHY} 3$ and ACCAU) as lineages basal to both of the clusters in the single-linkage method, and the inclusion of four populations of Gray-breasted Jays at various points within these clusters. The remaining populations of Gray-breasted Jays and the two east slope Unicolored Jay populations (ANCON and ANOAX) form a sister cluster to the two just described. Scrub Jay populations from Florida and Santa Cruz Island, and the Guerrero Unicolored Jay population fall outside all of these clusters.

Fitch-Margoliash analyses. - Analyses of the relationships of the 24 population samples of Scrub Jays (Fig. 3A) showed basal branches leading to the Santa Cruz Island and Florida populations (ACINS and ACCO2), and then branches to populations from the interior western United States, northern Mexico, and southern Mexico (woodhouseii and sumichrasti groups). Derived from within the latter group are the populations of the californica group. A jackknife manipulation of this data set preserves the same basic 


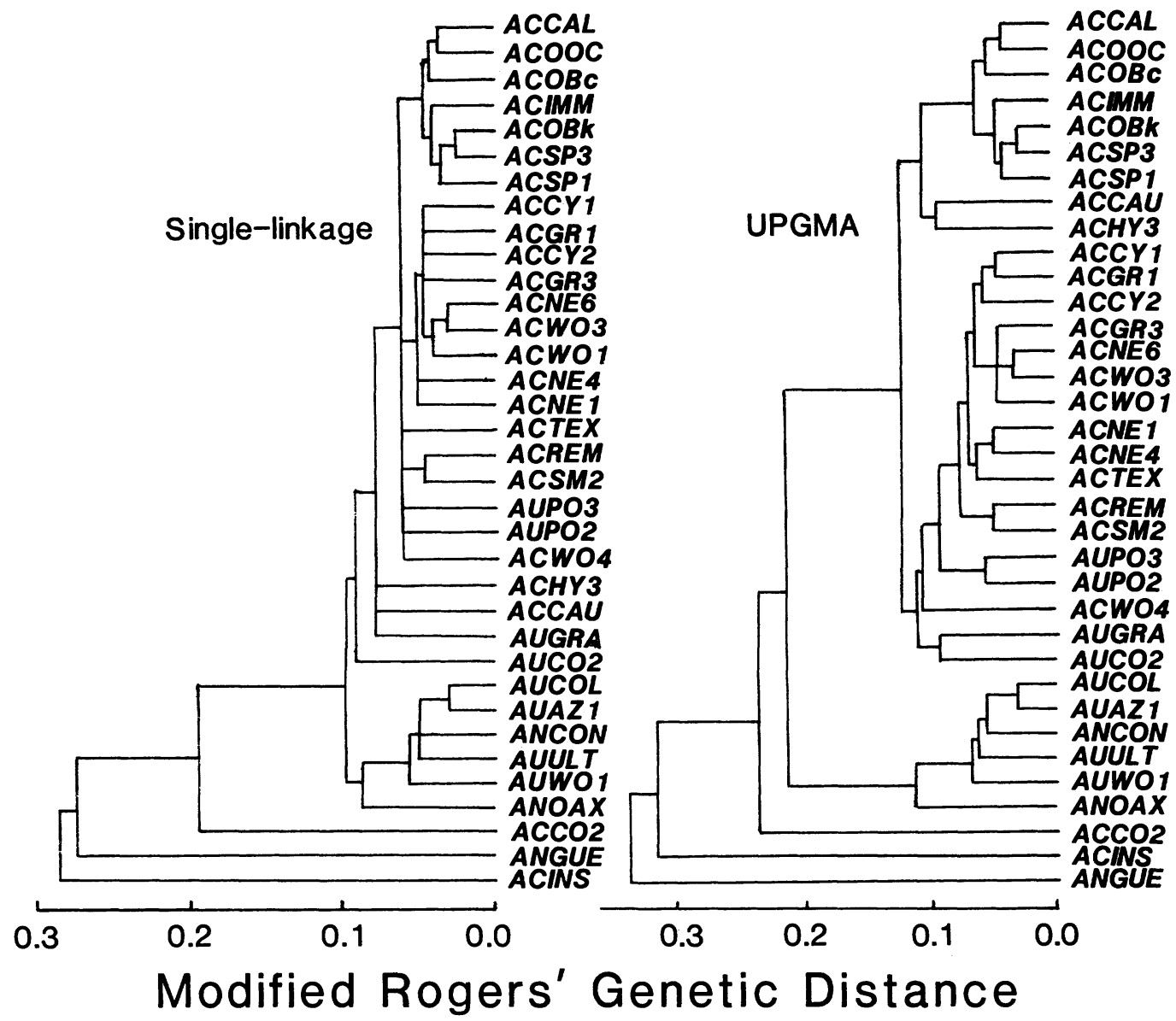

Fig. 2. Phenetic relationships among 35 populations of Aphelocoma jays based on (A) single-linkage cluster analysis and (B) UPGMA. See Table 1 for abbreviations.

structure, with 8 of the 23 nodes lost due to instability of the trees (Fig. 3A). Removal of populations with very long branches (Santa Cruz Island, ACINS, and Florida, ACCO2), as suggested by Swofford and Olsen (1990), preserves the same branching pattern in the remaining populations.

The eight populations of Gray-breasted Jays divided into two main lineages, one consisting of the two southern populations and AUAZ1, and the other of the eastern populations plus AUGRA and AUWO1 (Fig. 3B). None of the nodes was unstable under a jackknife manipulation. Analyses of the three Unicolored Jay populations indicated that the east-slope populations (ANOAX and ANCON) are sister taxa, well differentiated from the west-slope population (ANGUE, Fig. 3C).

The analysis of representatives from each subspecies group in the genus yielded unexpected results. Inclusion or exclusion of the basal-split populations ANGUE, ACINS, and $\mathrm{ACCO} 2$ did not change the placement of other taxa, so these populations were excluded from analysis. In nine replications (all jackknifed) of randomly chosen representatives of each subspecies group (for three examples, see Fig. 4), the southern Gray-breasted Jay population (AUCOL or AUULT) clustered with the Unicolored Jay population (ANCON or ANOAX), and the eastern Gray-breasted Jay population (AUPO2, AUPO3, or AUCO2) clustered with the various Scrub Jay populations. The western Gray-breasted Jay population (AUAZ1, AUGRA, or AUWO1) joined with the southern Gray-breasted Jay-Unicolored Jay group, joined with the Scrub Jay-eastern Gray-breasted Jay group, or separated in a basal trichotomy. Al- 


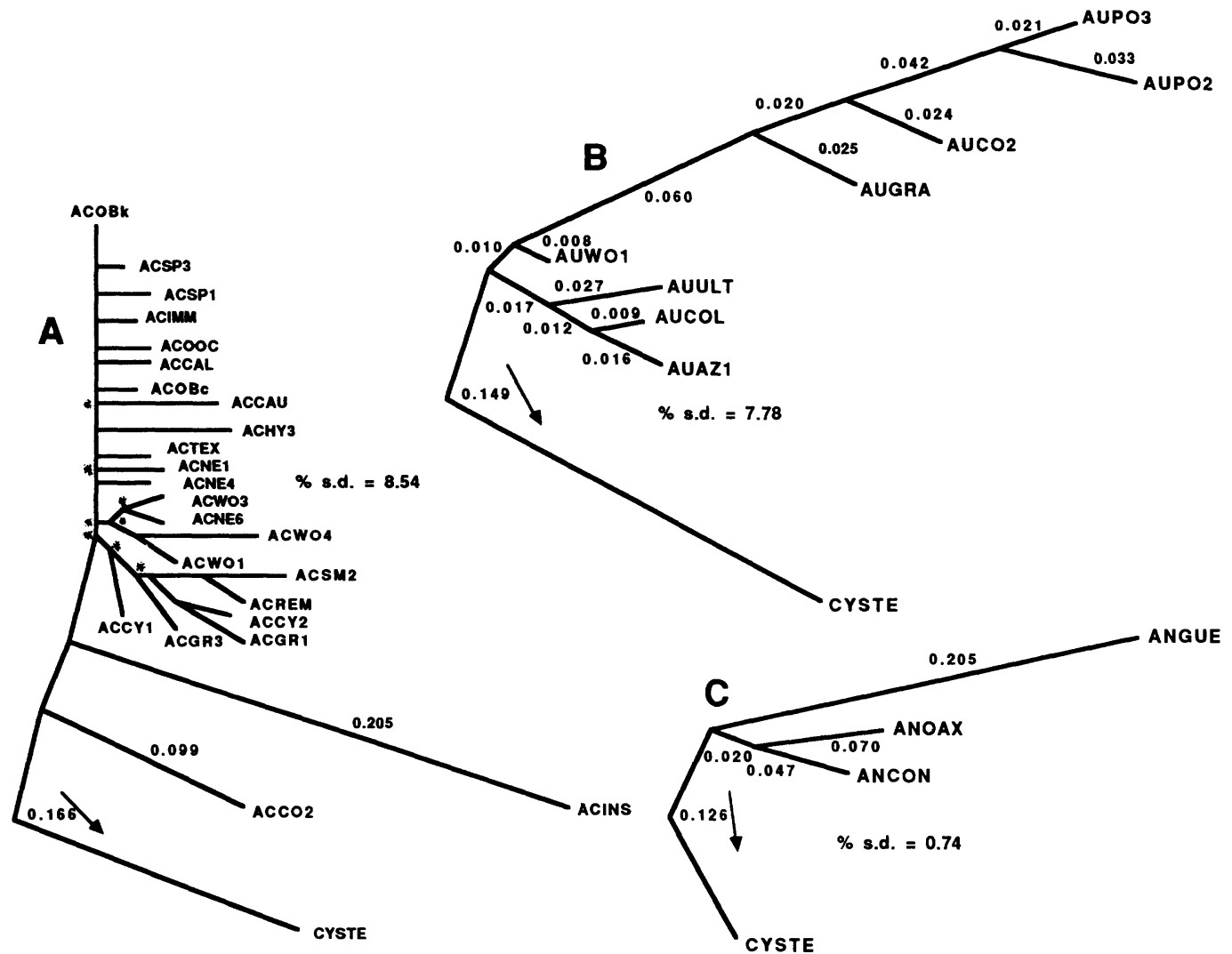

Fig. 3. Fitch-Margoliash analysis of relationships among populations within each of three species of Aphelocoma jays: (A) Scrub Jays; (B) Gray-breasted Jays; and (C) Unicolored Jays. Asterisks indicate nodes unstable to a jackknife manipulation. Numbers indicate fitted branch lengths; unmarked branches sized proportionally. CYSTE is Cyanocitta stelleri, the outgroup; see Table 1 for other abbreviations.

though the outgroup (CYSTE) is linked to the network in a fairly consistent position, it could be argued that inaccurate rooting could produce the paraphyly in Gray-breasted Jays. In this case, however, the two-branched form of the phylogeny makes any possible rooting lead to paraphyly in that species. From these results, I suggest that Gray-breased Jays represent a paraphyletic taxon that gave rise to both Scrub Jays and Unicolored Jays.

Cladistic analyses. - In cladistic analyses of relationships of the 35 individual populations, PAUP found at least 2,500 trees of 108 steps. A majority-rule concensus of these trees is shown in Figure 5. Of the 12 nodes in the concensustree, eight were retained in all jackknife pseudoreplicate analyses. The randomization test of Archie (1989) indicated the existence of significant phylogenetic information in the data $(P$ $\leq 0.03$ ).
These trees have several interesting features. First, they identify several pairs and trios of populations as sister taxa: central California and southern Baja California (ACCAL and ACHY3); northern and central Great Basin populations (ACNE1 and ACNE4); northern and southern Rocky Mountain populations (ACWO1 and ACWO4); southern Mexican populations of Scrub Jays (ACREM and ACSM2); and centralwestern Mexican (AUGRA and AUWO1) and eastern Mexican (AUPO2 and AUCO2 and then AUPO3) populations of Gray-breasted Jays. Many of these groupings correspond to those described based on morphology and geography (Pitelka 1951). Within the woodhouseii group, northern (ACNE1) and southern (ACNE4) nevadae populations are sister taxa, and northern (ACWO1) and southern (ACWO4) woodhouseii are also sister taxa. This finding confirms geographic patterns described by Pitelka (1951), and 

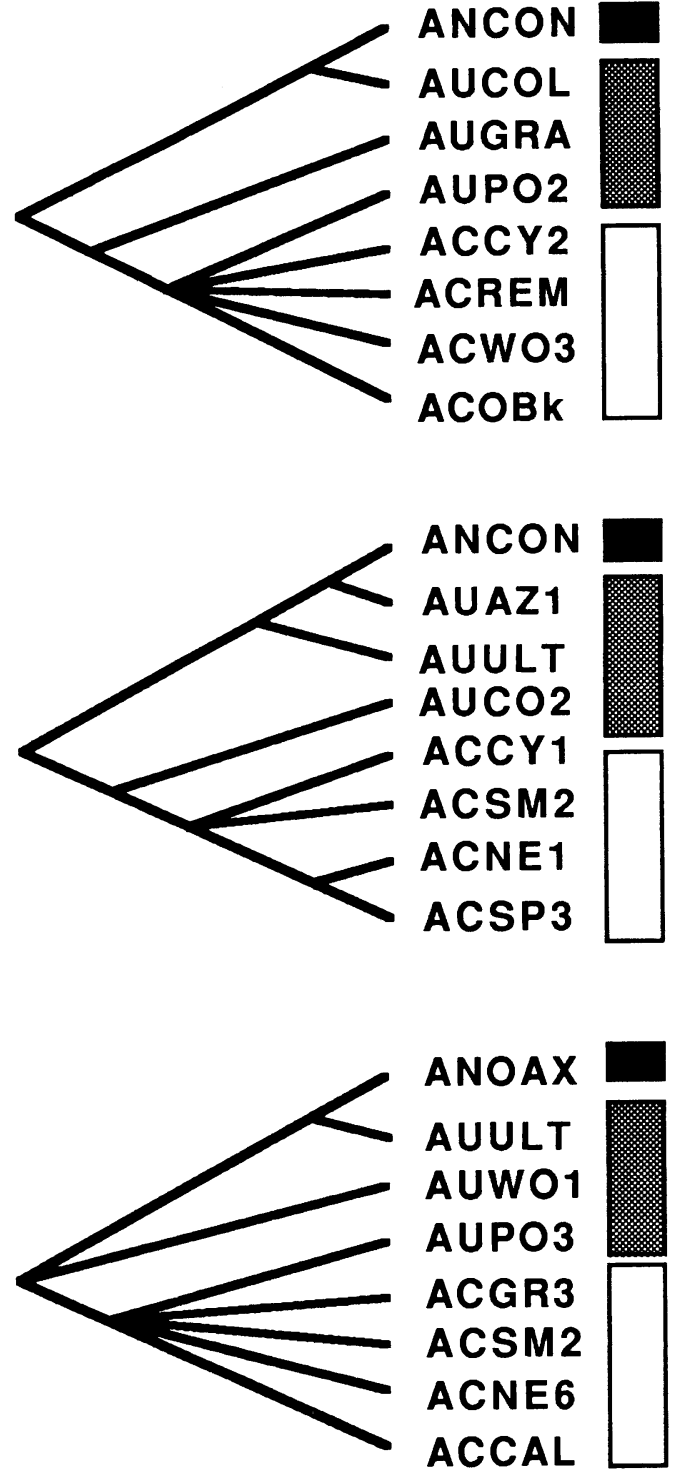

Fig. 4. Three replicate Fitch-Margoliash analyses with randomly chosen representative populations of eight subspecies groups of Aphelocoma jays. Bars indicate species membership: white, Scrub Jay; gray, Gray-breasted Jay; and black, Unicolored Jay. See Table 1 for abbreviations.

contradicts patterns described by Phillips (1986), who suggested that southern Great Basin (southern nevadae) and southern Rocky Mountain (southern woodhouseii) populations are more closely related to each other than to populations to the north.

In the original consensus tree and in 33 of 35 of the jackknife pseudoreplicates, the eastern

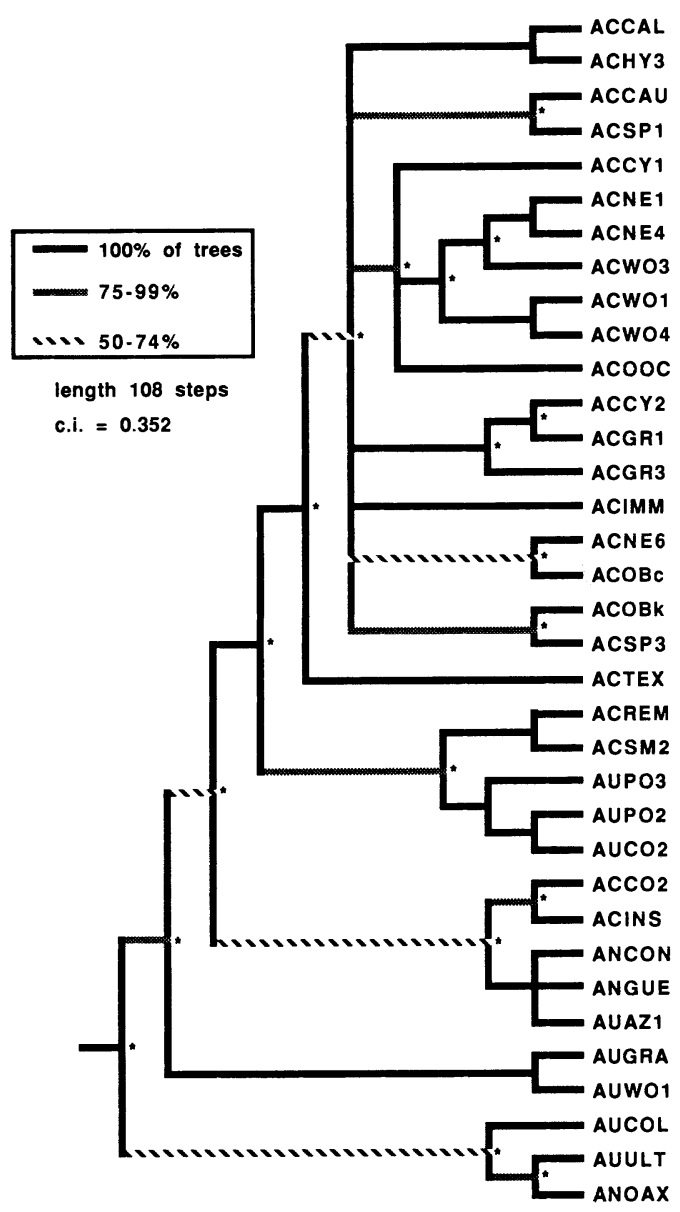

Fig. 5. Cladistic analysis of 35 Aphelocoma jay populations, based on binary coding of 38 alleles. A majority-rule consensus of 2,500 108-step trees shown by line type. Nodes marked with asterisk found to be unstable to a jackknife manipulation. See Table 1 for abbreviations. Consistency index (c.i.) indicated.

populations of Gray-breasted Jays are united with the Scrub Jay clade, making Gray-breasted Jays as a taxon paraphyletic (Fig. 5). In addition, in all trees examined, a northwestern Graybreasted Jay population sample (AUAZ1) groups with two Unicolored Jay populations (but see Discussion). Again, the exact position of the root does not change the paraphyly in Gray-breasted Jays. Therefore, the currently recognized species Gray-breasted Jay appears to be a paraphyletic taxon, with the other two recognized species derived from different populations within it.

Inspection of patterns of character evolution on this tree indicates that the Scrub Jay clade 
(minus ACTEX, ACREM, and ACSM2) is supported by two synapomorphies, and that several other internal nodes are supported by synapomorphic alleles. Because the GDA locus shows an odd pattern of variation in Graybreasted Jay populations (Peterson 1990), I became concerned that it might be responsible for the patterns of paraphyly in Gray-breasted Jays. This locus might be suspect because the two alleles observed differed in mobility by only about $2 \mathrm{~mm}$. (Several rechecks of allele homologies at maximum mobility failed to distinguish more than two alleles at this locus.) I reran the analyses omitting the information at the GDA locus. Although the strict consensus of the resulting 2,500 most-parsimonious trees is less well resolved than the overall analysis, AUAZ1 was still more closely related to two Unicolored Jay populations than to other Gray-breasted Jay populations (but see Discussion). A node uniting eastern Gray-breasted Jay populations with Scrub Jays was found in $69 \%$ of the trees. Therefore, support exists for the hypothesis of paraphyly of Gray-breasted Jays at loci other than GDA.

In analyses of relationships of the subspecies groups, PAUP found one 58-step tree (Fig. 6), nine 59-step trees, and many longer trees. The shortest tree is almost identical to those produced by the Fitch-Margoliash analyses (Fig. 4), but differs in that eastern and western Graybreasted Jays group together; it provides better resolution among populations of Scrub Jays. The 59-step trees differ in placement of a few branches, but the basic structure is similar. Several alleles provide support for most nodes, including 10 alleles that represent synapomorphies for all Scrub Jay populations except the sumichrasti group, and one to five synapomorphies that support other nodes (Fig. 6). A jackknife manipulation of the data set preserved the general structure of the tree, with two unstable nodes. The randomization test of Archie (1989) indicated the presence of significant phylogenetic information in the data set $(P<0.01)$. Omitting the two GDA alleles from analysis did not change the tree structure, except in that two nodes are unresolved.

Although the tree of the eight subspecies groups in the three species is well resolved, placement of the remaining three distinct lineages is equivocal. The Scrub Jays of Santa Cruz Island (ACINS) and Florida (ACCOE), and the Unicolored Jays of Guerrero (ANGUE) are in-

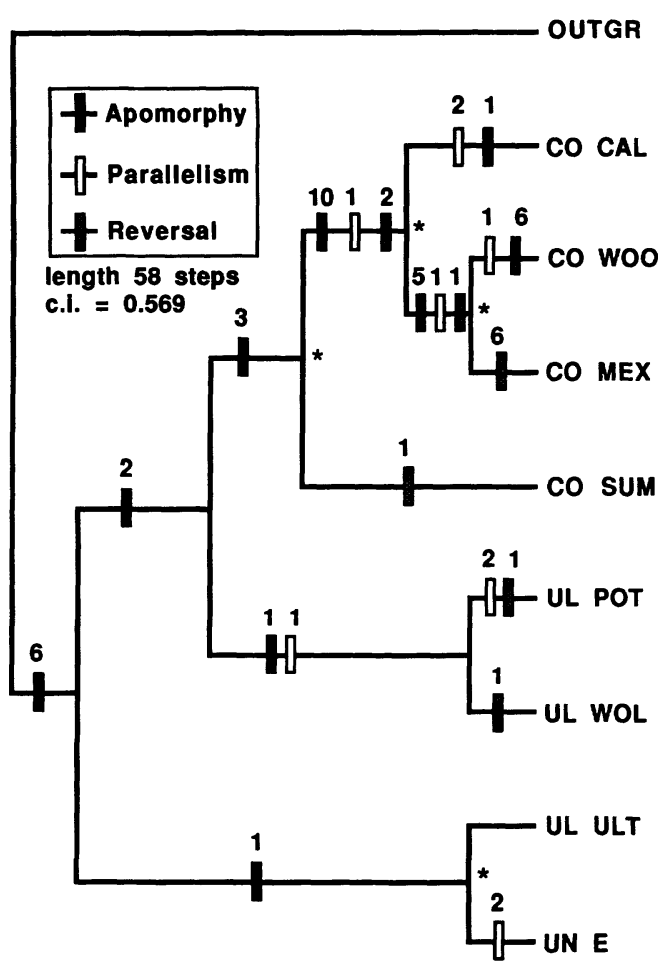

Fig. 6. Cladistic analysis of eight subspecies groups of Aphelocoma jays and outgroup showing characterstate changes and support for nodes. Nodes marked with asterisk found to be unstable to a jackknife manipulation. See Table 1 for abbreviations; consistency index (c.i.) indicated.

variably placed as basal offshoots of the trees (Fig. 7B). For reasons outlined below, this arrangement seems unlikely, so a placement of these three populations that agrees more closely with geography (Fig. 7A) is also considered in the analyses of rate uniformity.

Rates of molecular evolution.-Because the phylogenetic studies described above are equivocal as to the placement of three populations (ACINS, ANGUE, and ACCO2), I used both trees of Figure 7 in the rate tests. I conducted a relativerate test based on the following three-taxon statements (from Figs. 7A and 7B): ((ACINS, californica group), woodhouseii group); ((ANGUE, east-slope unicolor), southern Gray-breasted Jays); ((ACCO2, rest of Scrub Jays), eastern ultramarina); ((ACINS, rest of ingroup), CYSTE); ((ANGUE, rest of ingroup), CYSTE); and ((ACCO2, rest of ingroup), CYSTE). In the six tests, apparent departures from rate equality exist; ACINS, ANGUE, and ACCO2 in every comparison had greater genetic distances and pa- 


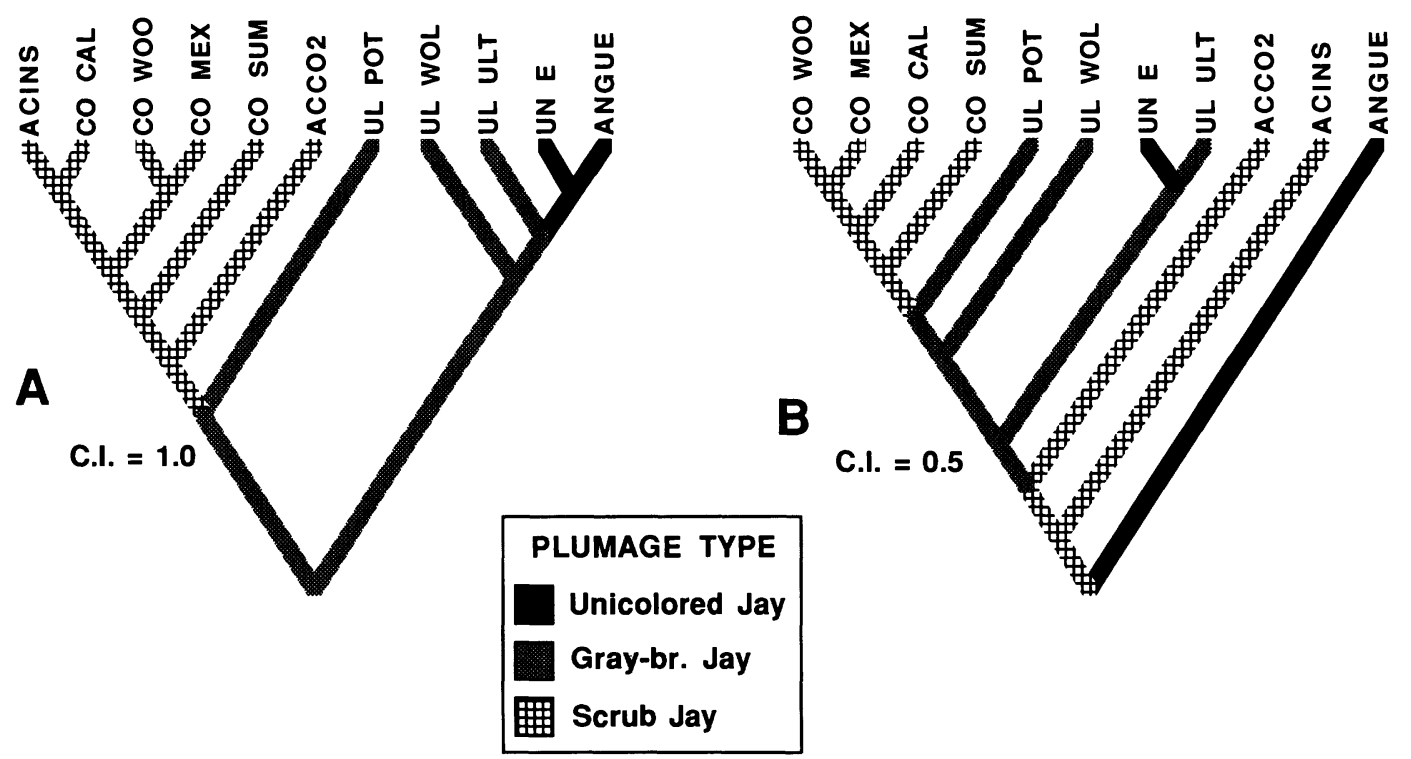

Fig. 7. Two possible phylogenies combining the results of Figures 2-6, showing most-parsimonious reconstructions of patterns of plumage evolution. Abbreviations follow Table 1; consistency index (c.i.) indicated.

tristic distances to the third taxon than did their sister lineages (sign test; all $P<0.001$ ). Presumably, higher rates of molecular evolution have characterized these three lineages relative to the rest of the group.

Analyses involving resampling of populations revealed a high degree of heterogeneity of rates among lineages (Fig. 8). Statistical comparisons indicate that evolutionary rates are significantly different in every pair of sister lineages (Mann-Whitney $U$-test; all $P<0.05$ ). The validity of these statistical tests depends on the effectiveness of the resampling manipulation in estimating true levels of branch-length variability. The manipulation employed here evaluates error introduced by choice of sample locality, but not sampling error in estimation of genetic distances. Nevertheless, it is clear that molecular evolutionary rates have been uneven in the history of the Aphelocoma jays.

\section{Discussion}

The consistency with which geographically related populations clustered together indicates that these data contain phylogenetic information. For example, in most analyses, the 10 woodhouseii-group populations cluster together, as do the nine californica-group populations. Below I discuss the unexpected features of the trees in an attempt to understand what factors, methodological or biological, led to those patterns.

Paraphyly of the Gray-breasted Jay. - In all analyses, the Gray-breasted Jay is a paraphyletic taxon. Unicolored Jays invariably group with the southern Gray-breasted Jay lineage, and Scrub Jays with the eastern Gray-breasted Jay lineage. The position of the western Gray-breasted Jay lineage is less clear. On the whole, it appears that the Gray-breasted Jay is a relatively old lineage that has been in the mountains of northern Mexico for a long period of time, and that Scrub Jays and Unicolored Jays were derived independently from different parts of the Graybreasted Jay complex.

Although unexpected (Pitelka 1951), this idea receives some support from other evidence. First, Gray-breasted Jays are intermediate in habitat use between the other two species. Where the three species' ranges overlap in central Veracruz, Scrub Jays live on dry interior slopes and Unicolored Jays on humid coastal slopes. Graybreasted Jays inhabit the pine-oak forests at higher elevations intermediate between the two, and so direct invasion of either habitat would have been possible. Second, Gray-breasted Jays in the southern and western portions of the range show delayed maturation of beak color, a character present in rudimentary form in Unicolored Jays and otherwise rare in birds (Pe- 
terson 1991b). Eastern Gray-breasted Jays do not delay beak color maturation, which is similar to the ontogenetic patterns of Scrub Jays (Peterson, in press). Similarly, western and southern Gray-breasted Jays do not give the femalespecific "rattle" vocalization, which is found in eastern Gray-breasted Jay and all Scrub Jay populations (Brown and Horvath 1989). Therefore, the hypothesis of independent derivations of Scrub and Unicolored jays from Gray-breasted Jays is supported by other characters. Taxonomic implications of these findings will be treated elsewhere (Peterson, in prep.).

Origin of the californica group of Scrub Jays.In a number of Fitch-Margoliash trees (e.g. Fig. 3), the californica group of Scrub Jays is derived from within the woodhouseii group of Scrub Jays. Some support for this hypothesis is also found in cladistic results although these nodes are not preserved in the consensus analyses (Fig. 5). This pattern is to be expected based on a probable Central American/Mexican origin of the species with subsequent invasion into the Great Basin and then into California (Peterson 1990).

Rapid evolution versus old splits. - Three disjunct populations-the Scrub Jays of Santa Cruz Island (ACINS), the Scrub Jays of Florida (ACCO2), and the Unicolored Jays of Guerrero (ANGUE) - consistently are placed as basal lineages in the phylogenetic analyses (Fig. 7; in a few alternative trees, the Florida population ACCO2 grouped with southern Mexican Scrub Jay populations based on one allele unique to the two groups). This result is surprising, given that each shares obvious similarities of plumage coloration, shape and size, vocalizations, and behavior with other members of its species. For example, ACINS shares several unique plumage characters with populations of California and, on that basis as well as on grounds of geographic proximity, seems to have been derived from adjacent mainland populations (Pitelka 1951). Two alternative hypotheses are apparent: (A) that these lineages are exceptionally divergent populations derived from within Scrub Jays and Unicolored Jays, but for nonhistorical reasons appear as basal splits on the trees (Fig. 7A); or (B) that these lineages are exceptionally old, and the characters that each shares with its conspecific populations are actually retained similarities (Fig. 7B). Alternative B is better supported by the allozyme data than alternative $A$ (treelength of 62 steps in $B ; 73$ steps in $A$ ).

Still, two biological points argue against al-
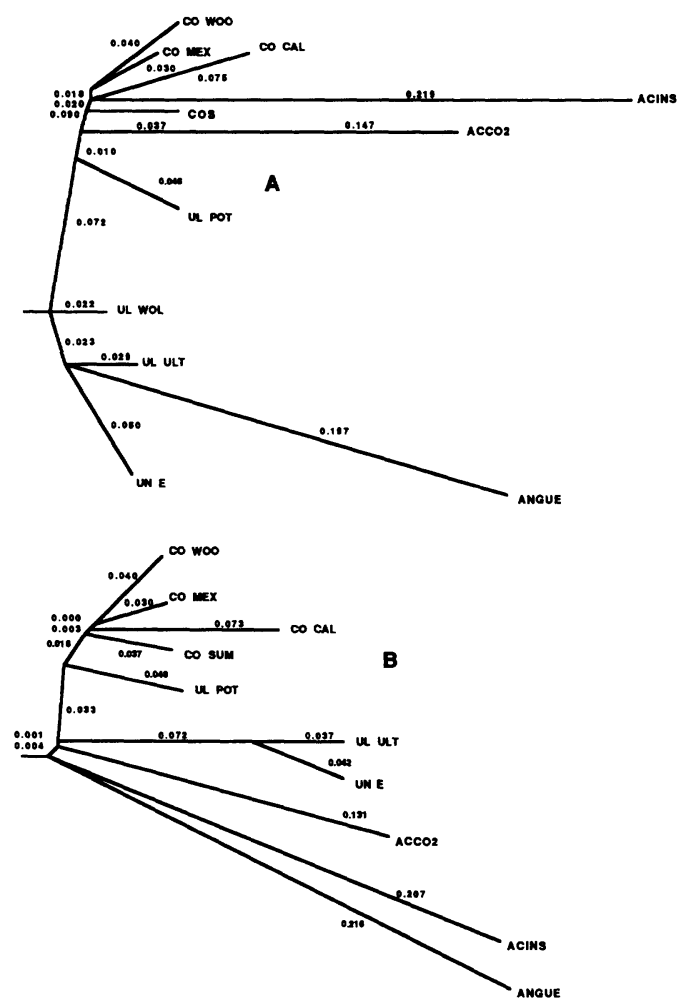

Fig. 8. Trees showing results of resampling analyses of rates of molecular evolution in different lineages, based on two trees of Figure 7. See Table 1 for abbreviations.

ternative B. First, although placement of these three populations as basal splits (Fig. 7B) reduces hypothesized levels of heterogeneity of rates of molecular evolution, it leads to problems in understanding the evolution of plumage coloration. For the tree in Figure 7B, plumage coloration must have undergone a number of reversals and episodes of rapid evolution (plumage coloration mapped onto tree; consistency index $=0.5$ ). Under the view in Figure 7A, plumage coloration shows only two changes: one at the derivation of Scrub Jays; and another at the derivation of Unicolored Jays (consistency index $=1.0$ ). Hence, hypothesis $B$ is less consistent with patterns of variation in plumage-color characters than hypothesis A. Furthermore, these populations share not only aspects of plumage coloration, but a wide range of characters (e.g. body size and shape, ecological requirements, vocalizations, behaviors) with conspecifics (Pitelka 1951), so whole suites of 
characters not included in my analyses would have had to have changed unpredictably.

Second, even if these populations represent basal splits (alternative B), they still have exceptional branch lengths. Unequal branch lengths can result from incorrect choice of outgroup (i.e. an outgroup taxon actually belongs to the ingroup). Outgroups in this study include representatives of the entire family Corvidae, so derivation of outgroup taxa from the ingroup is unlikely. Nevertheless, if to avoid unequal branch lengths, the trees are rerooted at the midpoint of the longest branch (in this case, that leading to ACINS or ANGUE), not only do at least two other ingroup taxa remain with exceptional branch lengths, but the outgroup appears as an exceptionally divergent branch derived from within Aphelocoma.

Removal of the three long branches from the tree (after Swofford and Olsen 1990) produces results that agree with geography and morphology. The populations on the three long branches all represent small, isolated populations isolated from the remainder of the species' ranges. Hence, I considered features of small populations that could possibly affect accurate reconstruction of phylogenies.

A possible resolution of these difficulties may lie in the extremely reduced levels of withinpopulation genetic variation in these same three populations (Peterson 1990). Heterozygosities for the three populations averaged 1.9, as compared with 3.9 for the remainder of the populations sampled (Mann-Whitney $U$-test, $P<0.05$; Peterson 1990). Other measures of within-population variation (e.g. proportion of loci polymorphic, number of alleles) are similarly reduced in the three populations. Many of the characters on which the phylogenies are based are alleles at low or moderate frequencies (e.g. PGD-e, which is found in all but one of californica-group populations, never at a frequency $>0.136$ ). If a population with low-frequency alleles that identify its sister-taxon relationships loses variation, perhaps due to population bottlenecks, those same low-frequency alleles would most likely be lost. Consequently, many of the characters shared with the ingroup (synapomorphies) are secondarily absent. These changes will move such lineages to the base of cladograms. Phenetic techniques that assume rate equality obviously will be sensitive to increases in evolutionary rates in particular lineages and, potentially, also to secondary losses of alleles. Thus, the tempo and mode of evolution in a group can affect the outcome of phylogenetic analyses; in this case, it leads to the basal placement of ACINS, ANGUE, and ACCO2.

This problem may affect other parts of the phylogenetic reconstruction of the Aphelocoma jays as well. For example, it could be responsible for the basal placement of ACTEX within Scrub Jays and the grouping of ANCON, ANGUE, and AUAZ1, all of which show reduced genetic variation (Fig. 5). Grouping of Florida and Santa Cruz Island populations (ACCO2 and ACINS) in some analyses (a most unlikely outcome geographically) is almost certainly a result of this phenomenon. Unexpected features of the phylogenies discussed above, such as the derivation of the californica group from the woodhouseii group and paraphyly of Gray-breasted Jays, most likely do not result from this problem because they do not involve groups that differ markedly in levels of genetic variability.

The best hypothesis for the position of ACINS, ACCO2, and ANGUE in the Aphelocoma jay phylogeny appears to be that they are exceptionally derived lineages from within Scrub Jays and Unicolored Jays. This conclusion is supported by several logical problems with the alternative hypothesis. The methodological reason for their basal placement in the analyses is clearly identifiable, and has nothing to do with time since divergence from the ancestral stock.

My results serve to illustrate some of the difficulties of using electrophoretic characters in phylogenetic analyses, as have been pointed out by other workers (e.g. Buth 1984, Swofford and Berlocher 1987, Swofford and Olsen 1990). The highly polymorphic nature of these characters makes coding and analysis difficult; effects of population history can reduce the probability of correctly reconstructing the history of the group. Although I believe that useful and accurate information was retrieved from the data set, the difficulty of exact placement of several important populations demands further study with other types of biochemical characters.

Rates of molecular evolution. - The analyses of rates of molecular evolution indicated that at least three Aphelocoma jay populations have undergone marked accelerations in rate of differentiation relative to their sister populations. Regardless of whether they are placed as basal splits or with apparently conspecific populations (Figs. 7B or 7A), these populations have 
evolved faster than other populations of Aphelocoma jays. Inspection of branch lengths in the tree (Fig. 8) suggests that heterogeneity of evolutionary rates may not be restricted to just those three lineages, but that rate heterogeneity on a finer scale may be common in the genus.

Because all tree-building methods are to some degree sensitive to rate differences (Swofford and Olsen 1990), trees estimated are not independent of the question of whether rates of evolution are uniform. When presented with a case of extreme rate inequality, algorithms for phylogeny estimation err on the side of reducing heterogeneity of branch lengths. A search for rate differences based on trees potentially affected by such differences is a conservative test; errors introduced will be of not finding a difference that exists, rather than of finding spurious heterogeneity. Studies of variation in other molecules that will permit critical independence of phylogeny estimation and branchlength estimation are in progress.

More interesting is the degree to which evolutionary rates differ. If ACINS and ANGUE represent basal splits from the genus, they have been evolving $20-25 \%$ more rapidly than the rest of the genus. If, as seems more likely, they were derived from within Scrub Jays and Unicolored Jays, their evolutionary rates have been three to four times greater than those of their sister lineages. Correlations between rate of differentiation and features of population biology are explored in Peterson (1990, in prep.).

Electrophoretic data for populations of Aphelocoma jays clearly violate the assumption of rate equality. Although studies of several other avian groups have come to the opposite conclusion (e.g. Bledsoe 1987), my results and the results of others (e.g. Britten 1986, Springer and Kirsch 1989 ) indicate that the assumption of rate uniformity is not always reasonable. Rate-dependent algorithms and interpretations should be tested first (e.g. Page 1990) and used cautiously, if at all, in studies purporting to derive phylogenetic or biogeographic information from molecular data alone.

\section{ACKNOWLEDGMENTS}

Many people have lent invaluable assistance to me during this project. I thank especially Scott M. Lanyon, Frank A. Pitelka, and John W. Fitzpatrick for their generous interest throughout the project. Thanks to John Bates, Shannon Hackett, Scott Lanyon, and two anonymous reviewers for helpful comments on the manuscript. I thank Pamela Austin, John Hall, Victor Pacheco, Mary Anne Rogers, Douglas Stotz, Thomas Schulenberg, David Willard, Adolfo Navarro S., and Patricia Escalante P. for their interest in my work. Shannon Hackett provided invaluable assistance with testing phylogenetic information in the cladistic data sets. I thank the Dirección de Flora y Fauna Silvestre, Secretaria de Desarollo Urbano y Ecología, of the Mexican government, and the state governments of Oregon, California, Nevada, Arizona, Utah, New Mexico, Colorado, and Texas for providing permits for scientific collecting. The Field Museum generously provided access to its facilities for biochemical analysis. Financial support was provided by the National Science Foundation Dissertation Improvement Grant Program (BSR-8700850), National Geographic Society, Field Museum of Natural History, Chapman Fund (American Museum of Natural History), Sigma $\mathrm{Xi}$, and the University of Chicago.

\section{LITERATURE CITED}

ARCHIE, J. W. 1989. A randomization test for phylogenetic information in systematic data. Syst. Zool. 38:239-252.

ARCHIE, J. W., C. Simon, AND A. MARTIN. 1989. Small sample size does decrease the stability of dendrograms calculated from allozyme-frequency data. Evolution 43:678-683.

BLEDSOE, A. H. 1987. DNA evolutionary rates in nineprimaried passerine birds. Mol. Biol. Evol. 4:559571.

BRITTEN, R. J. 1986. Rates of DNA sequence evolution differ between taxonomic groups. Science 231:1393-1398.

BRoOKs, D. R., AND D. A. MCLenNAN. 1990. Phylogeny, ecology, and behavior. Univ. Chicago Press, Chicago.

BRowN, J. L. 1987. Helping and communal breeding in birds. Princeton Univ. Press, Princeton, New Jersey.

Brown, J. L., AND E. G. HoRvath. 1989. Geographic variation of group size, ontogeny, rattle calls, and body size in Aphelocoma ultramarina. Auk 106:124128.

BuTH, D. G. 1984. The application of electrophoretic data in systematic studies. Annu. Rev. Ecol. Syst. 15:501-522.

Curtis, E. L., AND R. C. Miller. 1938. The sclerotic ring in North American birds. Auk 55:225-243.

FelsENSTEIN, J. 1979. Alternative methods of phylogenetic inference and their interrelationship. Syst. Zool. 28:49-62.

FELSENSTEIN, J. 1982. Numerical methods for inferring evolutionary trees. Q. Rev. Biol. 57:379-404. 
FELSENSTEIN, J. 1989. PHYLIP (phylogeny inference package), version 3.2 manual. Univ. Washington, Seattle.

Fitch, W., AND E. Margoliash. 1967. Construction of phylogenetic trees. Science 155:279-284.

FITZPATRICK, J. W., AND G. E. WOOLFENDEN. 1986. Demographic routes to cooperative breeding in some New World jays. Pages 137-160 in Evolution of animal behavior (M. H. Nitecki and J. A. Kitchell, Eds.). Oxford Univ. Press, Oxford.

HARDY, J. W. 1969. A taxonomic revision of the New World jays. Condor 71:360-375.

HARRIS, H., AND D. A. HoPKINSON. 1978. Handbook of enzyme electrophoresis in human genetics. North-Holland Publishing Co., Amsterdam.

HOPE, S. 1989. Phylogeny of the avian family Corvidae. Ph.D. dissertation, City Univ. New York, New York.

JOHNSON, N. K., AND J. A. MARTEN. 1988. Evolutionary genetics of flycatchers. II. Differentiation in the Empidonax difficilis complex. Auk 105:177-191.

LANYON, S. M. 1985. Detecting internal inconsistencies in distance data. Syst. Zool. 34:397-403.

Nevo, E., R. Ben-Shlomo, A. Beiles, J. U. M. Jarvis, AND G. C. HiCKMAN. 1987. Allozyme differentiation and systematics of the endemic subterranean mole rats of South Africa. Biochem. Syst. Ecol. 15:489-502.

PAGE, R. D. M. 1990. Temporal congruence and cladistic analysis of biogeography and cospeciation. Syst. Zool. 39:205-226.

PETERSON, A. T. 1990. Evolutionary relationships of the Aphelocoma jays. Ph.D. dissertation, Univ. Chicago, Chicago.

Peterson, A. T. 1991a. New distributional information on the Aphelocoma jays. Bull. Br. Ornithol. Club 111:28-33.

Peterson, A. T. 1991b. Sociality and ontogeny of coloration in the blue-and-black jays. Wilson Bull. 103:59-67.

PETERSON, A. T. 1992. Geographic variation in the ontogeny of beak coloration of Gray-breasted Jays (Aphelocoma ultramarina). Condor 93:448-452.

Peterson, A. T., AND N. VARgas B. 1992. Ecological diversity in Scrub Jays (Aphelocoma coerulescens). In Biological diversity of Mexico: Origins and distribution (T. P. Ramamoorthy, R. Bye, A. Lot, and J. Fa, Eds.). Oxford Univ. Press, Oxford.

PhIlliPs, A. R. 1986. The known birds of North and Middle America, vol. 1. A. R. Phillips, Denver.

PitelkA, F. A. 1951. Speciation and ecologic distribution in American jays of the genus Aphelocoma. Univ. Calif. Publ. Zool. 50:195-464.

RoHLF, F. J. 1988. NTSYS-pc: Numerical taxonomy and multivariate analysis system, version 1.40 . Exeter Software, Setauket, New York.
SARICH, V. M. 1977. Rates, sample sizes, and the neutrality hypothesis for electrophoresis in evolutionary studies. Nature 265:24-28.

Shaw, C. R., AND R. Prasad. 1970. Starch gel electrophoresis-A compilation of recipes. Biochem. Genet. 4:297-330.

Sheldon, F. H. 1987. Rates of single-copy DNA evolution in herons. Mol. Biol. Evol. 4:56-69.

Sibley, C. G., AND J. E. AHLQUist. 1981. The phylogeny and relationships of the ratite birds as indicated by DNA-DNA hybridization. Pages 301335 in Evolution today: Proceedings of the Second International Congress of Systematic and Evolutionary Biology (G. G. E. Scudder and J. L. Reveal, Eds.). Carnegie-Mellon Univ., Pittsburgh.

Sibley, C. G., AND J. E. Alquist. 1983. Phylogeny and classification of birds based on the data of DNA-DNA hybridization. Curr. Ornithol. 1:245292.

Sibley, C. G., J. E. Alquist, AND F. H. Sheldon. 1987. DNA hybridization and avian phylogenetics: Reply to Cracraft. Evol. Biol. 21:97-125.

SPRINGER, M. S., AND J. A. W. KIRSCH. 1989. Rates of single-copy DNA evolution in phalangeriform marsupials. Mol. Biol. Evol. 6:331-341.

SwOFFORD, D. L. 1989. PAUP: Phylogenetic analysis using parsimony, version 3.0. Illinois Natural History Survey, Champaign.

SWOFFORD, D. L., AND S. H. BERLOCHER. 1987. Inferring evolutionary trees from gene frequency data under the principle of maximum parsimony. Syst. Zool. 36:293-325.

SWOFFord, D. W., AND G. J. Olsen. 1990. Phylogeny reconstruction. Pages 411-501 in Molecular systematics (D. M. Hillis and C. Moritz, Eds.). Sinauer Associates, Sunderland, Massachusetts.

Woolfenden, G. E., AND J. W. FitzPatrick. 1984. The Florida Scrub Jay: Demography of a cooperative breeding bird. Princeton Univ. Press, Princeton, New Jersey.

Wilson, A. C., S. Carlson, and T. J. White. 1977. Biochemical evolution. Annu. Rev. Biochem. 46: 573-639.

WRIGHT, S. 1978. Evolution and the genetics of populations. Vol. 4, Variability within and among populations. Univ. Chicago Press, Chicago.

ZINK, R. M. 1982. Patterns of genic and morphologic variation among sparrows in the genera Zonotrichia, Melospiza, Junco, and Passerella. Auk 99: 632-649.

ZuCKerkandL, E., AND L. PAUling. 1962. Molecular disease, evolution, and genic heterogeneity. Pages 189-225 in Horizons in biochemistry (M. Kasha and B. Pullman, Eds.). Academic Press, New York. 